PAPER

\title{
A comparison of temperament in nonhuman apes and human infants
}

\section{Esther Herrmann, ${ }^{1}$ Brian Hare, ${ }^{2}$ Julia Cissewski ${ }^{1}$ and Michael Tomasello ${ }^{1}$}

1. Max Planck Institute for Evolutionary Anthropology, Leipzig, Germany

2. Department of Evolutionary Anthropology and Center for Cognitive Neuroscience, Duke University, USA

\begin{abstract}
The adaptive behavior of primates, including humans, is often mediated by temperament. Human behavior likely differs from that of other primates in part due to temperament. In the current study we compared the reaction of bonobos, chimpanzees, orangutans, and 2.5-year-old human infants to novel objects and people - as a measure of their shyness-boldness, a key temperamental trait. Human children at the age of 2.5 years avoided novelty of all kinds far more than the other ape species. This response was most similar to that seen in bonobos and least like that of chimpanzees and orangutans. This comparison represents a first step in characterizing the temperamental profiles of species in the hominoid clade, and these findings are consistent with the hypothesis that human temperament has evolved since our lineage diverged from the other apes in ways that likely have broad effects on behavior. These findings also provide new insights into how species differences in ecology may shape differences in temperament.
\end{abstract}

\section{Introduction}

In highly flexible species such as primates, adaptive responses to all aspects of the environment are governed by various motivations and emotions. Indeed, how a species or individual reacts emotionally to various environmental stimuli can play an important role in explaining differences in their behavioral phenotype (Kagan, 1994; Fairbanks, Newman, Bailey, Jorgensen, Breidenthal, Ophoff, Comuzzie, Martin \& Rogers, 2004; Hare, 2007). For example, a species of bird that fears brightly colored insects will also avoid eating species that are actually edible and eaten by other bird species (Krebs \& Davies, 1993). Or a human who is attracted to or enjoys public attention may be more likely to choose a career involving public speaking than one who shies away from such attention (Kagan \& Snidman, 2004).

There is a significant amount of research on temperament in species ranging from insects, cephalopods, and fish, to several mammals including humans (Gosling, 2001; Rothbart, Ahadi, Hershey \& Fisher, 2001; Réale, Reader, Sol, McDougall \& Dingemanse, 2007; Freeman \& Gosling, 2010). However, the definition of temperament varies within these studies from individual differences in behavioral styles that show continuity over time (Clarke \& Boinski, 1995; Thomas \& Chess, 1977) to more specific definitions like individual differences in reactivity and self-regulation which have a biological basis although affected by environment (Rothbart \&
Derryberry, 1981). The majority of research on temperament in humans and animals has focused on individual variability in behavioral styles within a single species (Gosling, 2001; Kagan \& Snidman, 2004). Very often surveys are utilized in which human observers rate individual temperamental traits in order to quantify individual variability (e.g. Crawford, 1938; Buirski, Plutchik \& Kellerman, 1978; Stevenson-Hinde, Zunz \& Stillwell-Barnes, 1980; Bolig, Price, O’Neill \& Suomi, 1992; Dutton, Clark \& Dickins, 1997; King \& Figueredo, 1997; Lilienfeld, Gershon, Duke, Marino \& de Waal, 1999; Gosling \& John, 1999; Rothbart et al., 2001; King, Weiss \& Farmer, 2005).

A second method is to examine individual behavioral variability by measuring behavioral responses e.g. to novelty or uncertainty (e.g. Yerkes \& Yerkes, 1936; Hebb, 1949; Singh \& Manocha, 1966; Glickman \& Sroges, 1966; Parker, 1974; Torigoe, 1985; Higley \& Suomi, 1989; Coleman \& Wilson, 1998; Fairbanks \& McGuire, 1993; Clarke \& Boinski, 1995; Trut, 1999; Rothbart, Derryberry \& Hershey, 2000; Fairbanks, 2001; Gosling, 2001; Kagan \& Snidman, 2004; Uher, Asendorpf \& Call 2008). Behavioral measures of responses to novelty or uncertainty such as approach or avoidance - often described along a continuum of shyness-boldness - are particularly useful in characterizing an important dimension of temperament in a variety of species (Clarke \& Boinski, 1995; Kagan \& Snidman, 2004; Réale et al., 2007). In vervet monkeys, individual variability in shyness-boldness has 
been attributed to heritable differences among individuals (Fairbanks et al., 2004). In humans, individual variability in shyness-boldness is one of the most stable behavioral traits from infancy into adulthood, is heritable and is associated with variance in physiology across individuals (Kagan, Reznick \& Snidman, 1988; Kagan, Reznick \& Gibbons, 1989; Robinson, Kagan, Reznick \& Corley, 1992; Kagan, 1997; Rothbart et al., 2000; Kagan \& Snidman, 2004). Cross-species comparisons in approach-avoidance behavior in novel situations have also revealed species differences that map onto foraging preferences, and also onto the degree to which species actively defend against predators - in ways that reflect the species' particular ecologies (Vitale, Visalberghi \& De Lillo, 1991; Clarke \& Lindburg, 1993; Clarke \& Boinski, 1995; Glickman \& Sroges, 1966; Mettke-Hofmann, Wink, Winkler \& Leisler, 2004).

Based on comparative behavioral research between chimpanzees and humans, it has recently been hypothesized that the temperament of humans may differ from that of other apes (Hare \& Tomasello, 2005; Hare, 2007). This hypothesis was inspired by research showing that in many contexts chimpanzee problem solving may be constrained by their emotional reactivity. Unlike humans, it seems that dominant chimpanzees cannot inhibit competitive tendencies while subordinates are too afraid to work with dominants who monopolize the spoils of joint efforts (Hare, Melis, Woods, Hastings \& Wrangham, 2007; Melis, Hare \& Tomasello, 2006). Moreover, unlike humans, chimpanzees seem to lack the emotions or motivation to become engaged in shared activities and cooperative communication (Hare \& Tomasello, 2004; Tomasello, Carpenter, Call, Behne \& Moll, 2005; Warneken \& Tomasello, 2006; Herrmann \& Tomasello, 2006).

However, it is still the case that very little is known about the different temperamental dimensions of nonhuman apes (see Freeman \& Gosling, 2010, for a review on nonhuman primate personality), and how this might compare with humans. First, inferences made from our behavioral research regarding the temperament of chimpanzees are all indirect or based on work with domesticated animals (Hare \& Tomasello, 2005). Second, there has been little systematic research directly measuring and comparing any species of nonhuman ape on any aspect of temperament (see these studies for species comparison of object manipulation: Glickman \& Sroges, 1966; Parker, 1974; Torigoe, 1985) and previous work within a species predominantly focused on chimpanzees (Yerkes \& Yerkes, 1936; Hebb, 1949; Lilienfeld et al., 1999; also see Uher et al., 2008, for a study of individual differences in personality traits that includes all four nonhuman ape species but does not compare them). A lack of data on other nonhuman apes is particularly problematic since humans' other closest relative, the bonobo, has been observed in similar behavioral research to display more human-like (as compared with chimpanzees) levels of social tolerance and risk avoidance (de Waal \& Lanting, 1997; Hare et al., 2007; Heilbronner, Rosati, Stevens, Hare \& Hauser, 2008; Wobber, Wrangham \& Hare, 2010a; Wobber, Hare, Maboto, Lipson, Wrangham \& Ellison, 2010b). Finally, there has never been a direct comparison between humans and any species of nonhuman ape on any set of temperament tasks (but see King, Weiss \& Sisco, 2008, for a comparison of chimpanzee and human personality).

In the current study, therefore, we directly compared chimpanzees, bonobos, orangutans, and 2.5-year-old human children in their response to novelty on a single set of tasks (the orangutans function as an important 'outgroup' as the only non-African hominoid). We focused our comparison with nonhuman apes to 2.5 -year-old children because this is precisely the age that we have documented that human social cognition, relevant for living in a cultural world, begins to surpass that of other apes (Herrmann, Call, Hernandez-Lloreda, Hare \& Tomasello, 2007). We hypothesized that the more skilful performance of infants may be related to the human temperament at this critical stage in human development as children begin deploying cultural cognition (i.e. language acquisition, etc.). This hypothesis is based on the relationship previously described between the performance on social cognitive tasks and temperamental variables between species (Hare \& Tomasello, 2005; Hare, 2007). Moreover, it is also based on the relationship between individual variation in infant temperament at this age and later performance in Theory of Mind tasks at 4 and 5 years of age (Wellman, Lane, LaBounty \& Olson, 2011). Specifically, we predicted that at 2.5 years of age, human infants would be uniquely shy relative to other apes because within humans it is a shy and more reserved temperament that predicts better social cognitive abilities later in life (Wellman et al., 2011). Moreover, previous behavioral comparisons and differences in the nonhuman apes' ecology predict that bonobos will be the most similar to humans temperamentally. Chimpanzees and orangutans are characterized as having evolved in more unpredictable feeding environments than bonobos and are more prone to make risky (bold) feeding choices or engage in conflict that could result in serious injury (White \& Wrangham, 1988; Malenky \& Wrangham, 1994; Wrangham \& Peterson, 1996; Wrangham, 1999; Wrangham, Jones, Laden, Pilbeam \& Conklon-Brittain, 1999; van Schaik, 2004; Rosati, Stevens, Hare \& Hauser, 2007, Heilbronner et al., 2008; Furuichi, in press).

\section{Experiment 1}

In this experiment we characterize the temperamental profiles of nonhuman apes. Therefore, we measured their shyness-boldness by directly comparing the reaction of bonobos, chimpanzees, and orangutans to different humans, food and novel objects. 


\section{Methods}

Participants

In Experiment 1, 24 bonobos (Pan paniscus), 24 chimpanzees (Pan troglodytes), and 24 orangutans (Pongo pygmaeus) participated (Table 1). The chimpanzee and orangutan individuals were selected from a larger sample (Herrmann et al., 2007) in such a way that the ages and sex matched as well as possible to the bonobo individuals (see Table S1 ESM for more details). The apes lived at different sanctuaries including Lola ya Bonobo sanctuary, DR Congo; Ngamba Island chimpanzee sanctuary, Uganda; Tchimpounga chimpanzee sanctuary, Republic of Congo; Orangutan Care Centre and Quarantine in Pasir Panjang, Kalimantan, Indonesia; and the Wolfgang Köhler Primate Research Center in Leipzig Zoo, Germany. All sanctuary apes are orphans, were born in the wild and came to the sanctuary after being confiscated from the illegal bushmeat and pet trade. They were all raised in a highly comparable way together with peers by humans after arriving at the sanctuary and kept interacting with their human caregivers each day (see Wobber \& Hare, 2011, for more details on the rearing and psychological health of orphan apes in sanctuaries). At the time of testing, all apes lived in social groups. During the day the vast majority of chimpanzees and bonobos at the sanctuary had access to large tracts of tropical forest (5-40 hectares), and the orangutans at the sanctuary were allowed to forage in a nearby forest block (20-80 hectares) on alternating days. Bonobos and orangutans at the Wolfgang Köhler Primate Research Center spent the day in $1680 \mathrm{~m}^{2}-2300 \mathrm{~m}^{2}$ outdoor areas, and in $230 \mathrm{~m}^{2}-256 \mathrm{~m}^{2}$ indoor areas which contained climbing structures and various enrichment facilities such as spinning treat logs. In the evening all apes at the sanctuary came back from the forest and stayed the night in $12 \mathrm{~m}^{2}-160 \mathrm{~m}^{2}$ indoor enclosures and the apes at the zoo stayed at night in a series of sleeping rooms (about $36 \mathrm{~m}^{2}$ ). Apes were never food deprived for any reason and they were fed, in addition to the food the apes at the sanctuary could eat in the forest, a variety of fruits, vegetables, and other species-appropriate foods two to four times daily. Water was either available ad libitum or was given to the subjects several times a day (since most of the apes at the sanctuary spent the day in the forest).

\section{Experimental design and procedure}

Subjects were either individually tested in a familiar room in their indoor enclosure or in the case of the sanctuary orangutans in a new room to which they were introduced prior to testing. A table was placed in front of the subjects at which they were presented with different humans, objects and food (Figure 1) representing the main categories apes deal with daily when interacting with people and their physical environment, including novel objects and various foods. At the beginning of each trial an experimenter called the subject's name and used small food pieces to attract subjects to a set starting position that was $\sim 1.3$ meters away from the table where items would be presented. Once the subject received a small food piece and was positioned, a second experimenter would conduct a test trial which always lasted 30 seconds (at the start of a trial the first experimenter would move out of sight). Each ape was tested on three different days which varied in the level of activity that took place during the items' presentation (human, objects and food were only visible on the first day, moved on the second day and could be touched on the third day) and participated in 29 different trials that were divided into four categories (human, food, object and human absent; see Table 2 for a description of each item and the order of presentation). The items within each category varied in their degree of familiarity (human items: familiar or unfamiliar human), the degree of novelty and excitement (object items: boring bland toy to colorful, loud exciting toys) and the degree of preference for food (food items: non-preferred or preferred food). Subjects were presented with a different test item in each trial but the order of presentation was the same for all subjects. In the trials of the categories object and food, an unfamiliar human was sitting behind a table and presented a novel object or food item to subjects in different ways. In trials of the category human, either a familiar human or an unfamiliar human was sitting behind a table. In the two trials of the category human absent, which served as a type of control, no human was present. Either the experimenter left the test area after

Table 1 The species, age, sex and location of the subjects participating in the experiments

\begin{tabular}{llll}
\hline Species & \multicolumn{1}{c}{ Age } & Sex & Location (\#) \\
\hline Bonobo (Pan paniscus) & Range $=3-22$ yrs. & 16 male; 8 female & Lola ya Bonobo (19) \\
Experiment 1 & mean $=6.4$ yrs & Leipzig Zoo (5) \\
Chimpanzee (Pan troglodytes) & Range $=3-19$ yrs. & 15 male; 9 female & Ngamba (7) \\
Experiment 1 & Mean $=6.5$ yrs & Orangutan Care Center and Quarantine (21) \\
Orangutan (Pongo pygmaeus) & Range $=3-16$ yrs. & 13 male; 11 female & Leipzig Zoo (3) \\
Experiment 1 & Mean $=6.8$ yrs. & 52 male; 53 female & Child laboratory, Leipzig, Germany (all) \\
Human children (Homo sapiens) & 2.5 years old & 7 male; 7 female & Day car centers, Leipzig, Germany (all) \\
Experiment 2 & 2.5 years old & &
\end{tabular}



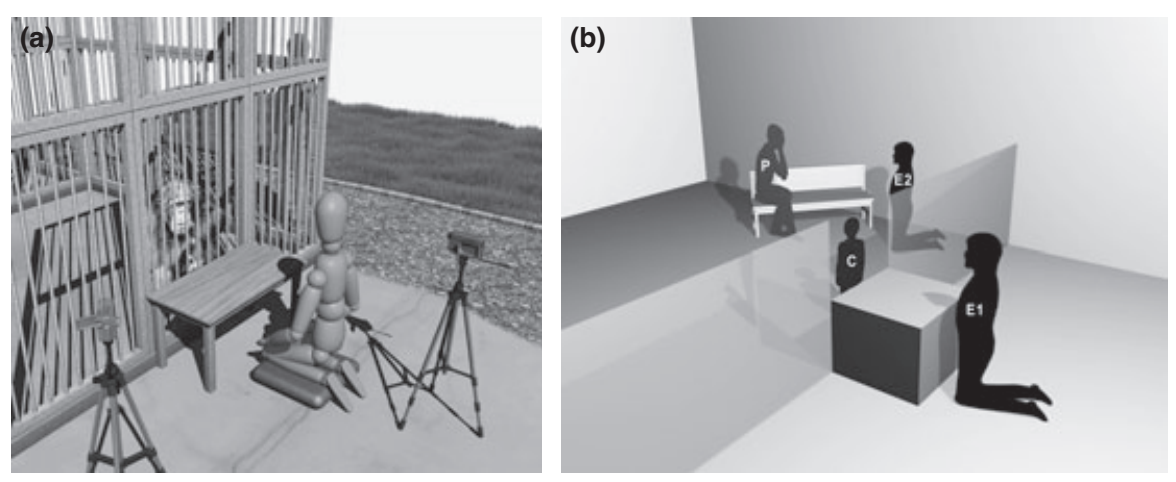

Figure 1 Experimental set-up for (a) the nonhuman apes in Experiment 1 and (b) the human children in Experiment 2. For all species the subject was positioned at a set starting point by an experimenter. This experimenter (E2) gave the nonhuman apes food and spoke in a friendly manner with the children while positioning them. Once positioned, the primary experimenter (E1) then presented items on a table in view of the subject at the starting point. In Experiment 1 the items were presented at the table that was separated from the subject by the mesh of the testing room. On day 1 (visible) and 2 (move), items were placed out of reach of the subject and on day 3 (touch) items were placed close to the mesh, hence being accessible to the subject. In Experiment 2 the items were presented at a table that on day 1 (visible) and 2 (move) was separated from the children by a Plexiglas wall which was removed on day 3 (touch) to allow the child access to the table. In Experiment 3 the table was high enough so that subjects could only see but not touch items so that Plexiglas was not used.

Table 2 Test items and their procedural description. All items were used in Experiment 1 while an * indicates the 11 items used with children tested in the child lab in Experiment 2 and bold indicates the five items that were used with children tested in day care in Experiment 3. The order of presentation started each day with the human items followed by object, food and human absent items

\begin{tabular}{|c|c|c|c|c|}
\hline Category & Item & Visible (Day 1) & Move (Day 2) & Touch (Day 3) \\
\hline Human items & $\begin{array}{l}\text { (1) Familiar human (keeper) } \\
\text { (2) Unfamiliar human } \\
\text { (experimenter) } \\
\text { (3) Hand* } \\
\text { (4) Body }\end{array}$ & $\begin{array}{l}\text { (1) Familiar human and } \\
\text { then (2) Unfamiliar human } \\
\text { sat behind test table, with } \\
\text { hands on her/his lap gazing } \\
\text { strait ahead. }\end{array}$ & $\begin{array}{l}\text { Unfamiliar human sat behind } \\
\text { test table *(1) moved her } \\
\text { right hand from the left side } \\
\text { to the right side and back on } \\
\text { the table and then }(2) \\
\text { bounced up and down while } \\
\text { seated. }\end{array}$ & $\begin{array}{l}\text { (1) Unfamiliar human sat } \\
\text { behind the table and put } \\
\text { her right fist on test table } \\
\text { within the subject's reach. }\end{array}$ \\
\hline Object items & $\begin{array}{l}\text { (1) Film canister * } \\
\text { (2) Plastic hedgehog* } \\
\text { (3) Police car *(for human } \\
\text { children, the car was covered } \\
\text { by a colorful cardboard box, } \\
\text { so that its appearance was } \\
\text { novel for the children) } \\
\text { (4) Box }\end{array}$ & $\begin{array}{l}\text { Unfamiliar human sat behind } \\
\text { test table, hands on her lap } \\
\text { with *(1) film canister *(2) } \\
\text { plastic hedgehog and then } \\
*(3) \text { police car placed in the } \\
\text { middle of the table. A remote } \\
\text { control activated the toy } \\
\text { police car horn and lights ten } \\
\text { times. }\end{array}$ & $\begin{array}{l}\text { Unfamiliar human sat behind } \\
\text { the table, moved } *(1) \text { film } \\
\text { canister } *(2) \text { hedgehog from } \\
\text { the left to the right and back } \\
\text { on the table and then moved } \\
*(3) \text { police car from the left } \\
\text { to right on the table. Then the } \\
\text { car was put back on the left } \\
\text { side and the action was } \\
\text { repeated. A remote control } \\
\text { activated the toy police car } \\
\text { so that it moved on its own } \\
\text { volition across the table. }\end{array}$ & $\begin{array}{l}\text { Unfamiliar human sat behind } \\
\text { the table, hands on her lap } \\
\text { with the *(1) film canister, } \\
*(2) \text { plastic hedgehog, } *(3) \\
\text { police car and then }(4) \text { box } \\
\text { placed on the table within } \\
\text { reach of the subject. }\end{array}$ \\
\hline Food items & $\begin{array}{l}\text { (1) Undesirable food } \\
\text { (2) Fruit piece } \\
\text { (3) Three peanuts } \\
\text { (4) Whole coconut }\end{array}$ & $\begin{array}{l}\text { Unfamiliar human sat behind } \\
\text { test table, hands on her lap } \\
\text { with (1) undesirable food ( } 2) \\
\text { fruit and then (3) three } \\
\text { peanuts placed in the middle } \\
\text { of the table. }\end{array}$ & $\begin{array}{l}\text { Unfamiliar human sat behind } \\
\text { test table, moved (1) } \\
\text { undesirable food, (2) fruit } \\
\text { and then (3) three peanuts } \\
\text { from left to right and back } \\
\text { on the table. }\end{array}$ & $\begin{array}{l}\text { Unfamiliar human sat behind } \\
\text { test table, hands on her lap } \\
\text { with (1) undesirable food ( } 2) \\
\text { fruit (3) three peanuts and } \\
\text { then (4) a coconut placed on } \\
\text { the table within reach of the } \\
\text { subject. }\end{array}$ \\
\hline $\begin{array}{l}\text { Human } \\
\text { absent items }\end{array}$ & $\begin{array}{l}\text { (1) Red spot } \\
\text { (2) Nothing * }\end{array}$ & $\begin{array}{l}\text { (1) Unfamiliar human placed } \\
\text { red spot on test table and } \\
\text { leaves testing area } \\
\text { *(2) Only the test table was } \\
\text { present during trial. }\end{array}$ & & \\
\hline
\end{tabular}

placing a novel object on the table or, in a second trial, only the table itself was present (see Table 2).

\section{Scoring and analysis}

Subjects' behavior was coded from video taken by two cameras positioned the same way across all testing sites.
One camera was centered behind the testing table such that it could film a rectangle of $140 \mathrm{~cm} \times 110 \mathrm{~cm}$ inside the testing room; this allowed us to record a predetermined area for later coding and the second camera filmed a global view of the testing area including the starting place. From the video we coded the subject's latency to enter this predetermined area after the start of 
the trial as a standardized measure of their approach behavior in the different test items (see ESM for further analysis of approach duration and proximity). Latency was measured as the interval between the starting time when the human/object/food/human absent were presented and the first time any part of the subject could be seen entering the predetermined space as they left their standardized starting point 1.3 meters away. For the majority of analyses the mean latencies for all items within a category were combined for comparison and two-tailed statistics were used (ESM). A second observer independently scored $20 \%$ of the trials resulting in high levels of inter-observer reliability (ESM, Table S2).

\section{Results}

Table 3 and Figure 2 show the mean latencies for bonobos, chimpanzees and orangutans to approach items within the four categories (food, object, human and human absent) as well as for the familiar human and unfamiliar human items. The species differed from one another in their latencies to approach across the different categories of items presented. An overall repeated measures ANOVA, with category (food, object, human and human absent) as the within-subjects variable and species and sex as the between-subjects variables, found a main effect of category $\left(F_{2.3}, 151.8=31.739, p<.001\right)$ and species $\left(F_{2,66}=5.756, p=.005\right)$, but no significant differences were detected for sex and no interaction between the three factors. Specifically, chimpanzees and orangutans approached food and novel objects more quickly than bonobos. Since no sex effect was found, this variable was not included in the following analyses. When considering each category of items separately, subjects differed in their latency to approach when an unfamiliar human presented food or objects (food: $F_{2,69}=19.415$, $p<.001, \eta^{2}=0.36$; object: $F_{2,69}=10.737, p<.001$, $\left.\eta^{2}=0.24\right)$ but not when only a human was present or absent. Post-hoc tests revealed that chimpanzees and orangutans approached the unfamiliar human with food or objects more quickly than bonobos $(p<.007$, Dunnett $\mathrm{t} 3$ corrections) but did not differ from one another in how they approached a human alone or the test table when no human was present.

When using approach latencies in the human absent category as a baseline (no human was present in either item), chimpanzees and orangutans differed most dramatically from their baseline approach behavior (Table 3; Figure 2). Chimpanzees and orangutans both approached more quickly in the food and object items

Table 3 Comparisons of approach latency (for nonhuman apes) and latency to respond positively (for human children) between the different species across categories of test items. Table 3a lists mean latencies to approach/respond positively to items in each category of test item listed by species and experiment (children were not examined in Experiment 1). Superscripts $(B, C, O, C H)$ indicate if the mean of one species' response was significantly faster than for another species. Table $3 b$ lists comparisons for each species between all of the test categories and the baseline test item in which no human was present at the testing table. Data are only presented for Experiments 1 and 2 since no baseline was conducted in Experiment 3. Superscripts indicate if a species was faster to approach/showed a positive response in the direction to the testing table in either the test categories $(F, O$, or $H)$ or in the baseline item in which no human was present at the testing table (B)

\begin{tabular}{|c|c|c|c|c|}
\hline & Bonobo (B) & Chimpanzee (C) & Orangutan (O) & Children $(\mathrm{CH})$ \\
\hline \multicolumn{5}{|l|}{ Experiment 1} \\
\hline Food items & 12.30 & $5.22^{\mathrm{B}}$ & $4.98^{\mathrm{B}}$ & - \\
\hline Object items & 14.97 & $6.98^{\mathrm{B}}$ & $8.05^{\mathrm{B}}$ & - \\
\hline Human items & 16.43 & 11.84 & 13.58 & - \\
\hline Human absent (baseline) & 16.86 & 12.29 & 14.29 & - \\
\hline Unfamiliar human & 19.04 & $11.46^{\mathrm{B}}$ & 13.42 & \\
\hline \multicolumn{5}{|l|}{ Experiment 2} \\
\hline Object items & $15.59^{\mathrm{H}}$ & $7.38^{\mathrm{H}, \mathrm{B}}$ & $8.50^{\mathrm{H}, \mathrm{B}}$ & 23.97 \\
\hline Human items & $13.92^{\mathrm{H}}$ & $9.38^{\mathrm{H}}$ & $11.42^{\mathrm{H}}$ & 27.92 \\
\hline Human absent (baseline) & 19.33 & 17.13 & 20.38 & 17.89 \\
\hline \multicolumn{5}{|l|}{ Experiment 3} \\
\hline Object items & 18.49 & $7.24^{\mathrm{H}, \mathrm{B}}$ & $8.83^{\mathrm{H}, \mathrm{B}}$ & 22.52 \\
\hline Human items & $20.67^{\mathrm{H}}$ & $15.21^{\mathrm{H}}$ & $17.63^{\mathrm{H}}$ & 29.54 \\
\hline & Bonobo & Chimpanzee & Orangutan & Children \\
\hline \multicolumn{5}{|l|}{ Experiment 1} \\
\hline Food items (F) vs. Baseline (B) & $p=.031^{\mathrm{F}}$ & $p<.001^{\mathrm{F}}$ & $p<.001^{\mathrm{F}}$ & - \\
\hline Object items (O) vs. Baseline (B) & ns & $p=.001^{\mathrm{O}}$ & $p<.001^{\mathrm{O}}$ & - \\
\hline Human only (H) vs. Baseline (B) & $n s$ & ns & $n s$ & - \\
\hline Familiar (F) vs. Unfamiliar human (U) & $n s$ & $p=.008^{\mathrm{U}}$ & $p=.034^{\mathrm{U}}$ & - \\
\hline \multicolumn{5}{|l|}{ Experiment 2} \\
\hline Object items (O) vs. Baseline (B) & $n s$ & $p<.001^{\mathrm{O}}$ & $p<.001^{\mathrm{O}}$ & $p<.001^{\mathrm{B}}$ \\
\hline Human only (H) vs. Baseline (B) & $n s$ & $p=.005^{\mathrm{H}}$ & $p<.001^{\mathrm{H}}$ & $p<.001^{\mathrm{B}}$ \\
\hline
\end{tabular}




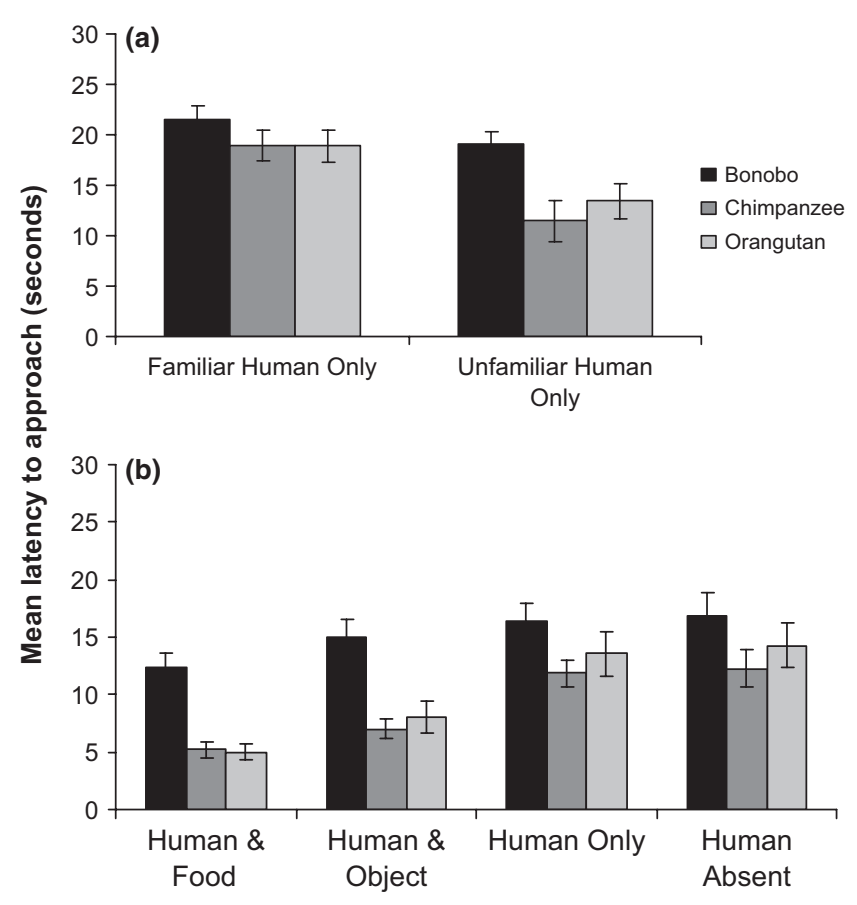

Figure 2 Experiment 1: The mean latency for bonobos, chimpanzees and orangutans to approach the testing table within 30 seconds in trials where (a) a familiar or unfamiliar human was present at the testing table and (b) an unfamiliar human with food, an unfamiliar human with a novel object, only an unfamiliar human, or no human was present at the testing table.

than in the baseline items (chimpanzee - food: $t(23)=5.368, p<.001 ;$ object: $t(23)=3.786, p=.001$; orangutan - food: $t(23)=5.867, p<.001$; object: $t(23)=5.085, p<.001$, paired-sample $t$-test). Neither species' approach behavior differed from the baseline when compared to the human items when only a human was present at the test table (chimpanzee: $t(23)=0.278$, $p=.784$; orangutan: $t(23)=0.550, p=.587$, pairedsample $t$-test). Meanwhile, bonobos only approached slightly more quickly than their baseline in the food items, but did not differ from the baseline in the other categories (food: $t(23)=2.305, p=.031$, paired-sample $t$-test).

When comparing the approach behavior of subjects in the items when only a familiar or unfamiliar human (keeper or experimenter, who was unfamiliar to the subject at the beginning of the experiment) was present, chimpanzees and orangutans both were quicker to approach an unfamiliar human than the bonobos. First, the three species differed in their approach behavior in the unfamiliar human item $\left(F_{2,68}=3.620, p=.032\right.$, $\left.\eta^{2}=0.10\right)$, whereas there were no species differences in the familiar human item $\left(F_{2,68}=0.454, p=.637\right.$, $\left.\eta^{2}=0.01\right)$. Post-hoc tests for the unfamiliar human item revealed that chimpanzees approached the unfamiliar human more quickly than bonobos $(p=.036$, Dunnett t3 correction) while orangutans did not differ significantly from either species (Figure 2). Second, both chimpanzees and orangutans approached an unfamiliar human more quickly than a familiar one (chimpanzee: $t(23)=2.907, \quad p=.008 ; \quad$ orangutan: $t(23)=2.256$, $p=0.034)$ while the approach behavior of bonobos did not differ between the two items (Table 3; Figure 2). Further analyses of approach duration and proximity are available online since they largely replicated the results for latency in this and subsequent experiments (see ESM).

\section{Discussion}

Overall then, with the exception of the 'human absent' or baseline items in which there were no species differences, orangutans and chimpanzees reacted more similarly to one another in their approach behavior than either did to the bonobos, with sex having no effect. While all three species approached food more quickly than in the baseline condition, chimpanzees and orangutans still approached food items significantly faster than bonobos. In addition, chimpanzees and orangutans approached object items more quickly in comparison to both baseline items and the bonobos, largely because bonobos did not differ in their approach behavior for the baseline and object items. Moreover, while there were no overall species differences in approach behavior in the human items, there were important differences when examining the species' response to a familiar and unfamiliar experimenter. Both chimpanzees and orangutans approached an unfamiliar experimenter more quickly than a familiar experimenter, while bonobos were again indifferent, approaching both types of experimenter in a similar amount of time. Therefore, based on their approach behavior relative to the baseline and each other, chimpanzees and orangutans can be characterized as being attracted to novelty while bonobos are largely indifferent to the stimuli presented here (i.e. bonobos had tendencies to be slightly attracted to novelty, particularly when food was present, but no evidence of avoiding novelty).

\section{Experiment 2}

Experiment 1 identified the temperamental similarities and differences across three nonhuman ape species in their response to novelty. Since it has been hypothesized that the human temperament differs in important ways from that of other nonhuman apes and that these changes in human temperament were a prerequisite for the expression of more complex and unique forms of human cognition (Hare \& Tomasello, 2005; Hare, 2007), we investigated the response to novelty of 2.5 -year-old human children on a subset of the tasks from Experiment 1 . We then compared these behaviors to those of bonobos, chimpanzees and orangutans, in order to map out similarities and differences in the species temperament. 


\section{Methods \\ Participants}

In a second experiment, 105 2.5-year-old human children (range $=$ within 2 months) participated. The human children were tested in a child laboratory in the Developmental and Comparative Psychology Department at the Max Planck Institute for Evolutionary Anthropology, Leipzig, Germany. The human children were recruited by telephone from an existing database. They were accompanied by a parent throughout the study (Table 1, Figure 1, ESM).

\section{Experimental design and procedure}

Each child was presented with a species-appropriate subset of items (fewer items and no items of the category food were used) that were previously presented to the nonhuman apes in Experiment 1. The experimental procedure was identical to that used with the nonhuman apes with the following exceptions: (1) the child's parent was present but sat behind the child to minimize any influence they might have on the subject's behavior during the test (parents were instructed not to interact with children during test trials); (2) the child sat at the starting position in each trial on a small bench and the second experimenter remained in the room during each trial; (3) before the testing days began, the child and an experimenter played together with a ball for 2 minutes in order to familiarize the child with the novel testing room; and (4) each subject only participated in 11 items from Experiment 1 (always administered in the same order; Table 2). For analysis the items were grouped into three categories: human items (unfamiliar human), object items (film canister, plastic hedgehog and police car), and human absent item (only table). Otherwise, like the apes, children were presented with items for 30 seconds after a second experimenter helped position them at a starting point $\sim 1.3$ meters away from the presentation. In case the child walked around the room before the beginning of a trial, the second experimenter directed her/him to the starting position by showing and talking about her stop watch. Trials started once subjects were seated on a bench and the second experimenter looked away from the child.

\section{Scoring and analysis}

Subjects' behavior was coded from video taken with one camera that filmed the complete testing area. The same predetermined rectangle of $140 \mathrm{~cm} \times 110 \mathrm{~cm}$ inside the testing room as in Experiment 1 was now marked on the floor and visible on the video for later coding. The coding criteria were similar to those used in Experiment 1 , but included some additional behavioral responses for the human children. First, the children's positive gestural and verbal responses during the test were also coded. A positive reaction was coded if the child pointed towards the stimuli presentation, talked about it, stood up in the direction of the presentation or spent time in the predetermined spatial area near the stimuli. Latency was defined as the interval between the starting time and the first time the children showed a positive reaction. We then replicated the analysis of Experiment 1 comparing all four species' response behavior (defined as approach for nonhuman apes and as positive reaction for human children) against each other on this subset of 11 items (see ESM for further analysis of duration of positive response and proximity). A second observer independently scored $20 \%$ of the human children trials resulting in high levels of inter-observer reliability (ESM, Table S5).

\section{Results}

Table 3 and Figure $3 \mathrm{~b}$ show the mean latencies for bonobos, chimpanzees, orangutans and human children to respond positively to items within the three categories: object items, human items and human absent item. Comparing the nonhuman ape data to the human children ones, a repeated measures ANOVA, with category (object, human and human absent) as the within-subjects variable and the four species and sex as the betweensubjects variables, found a main effect of category $\left(F_{1.5}\right.$,

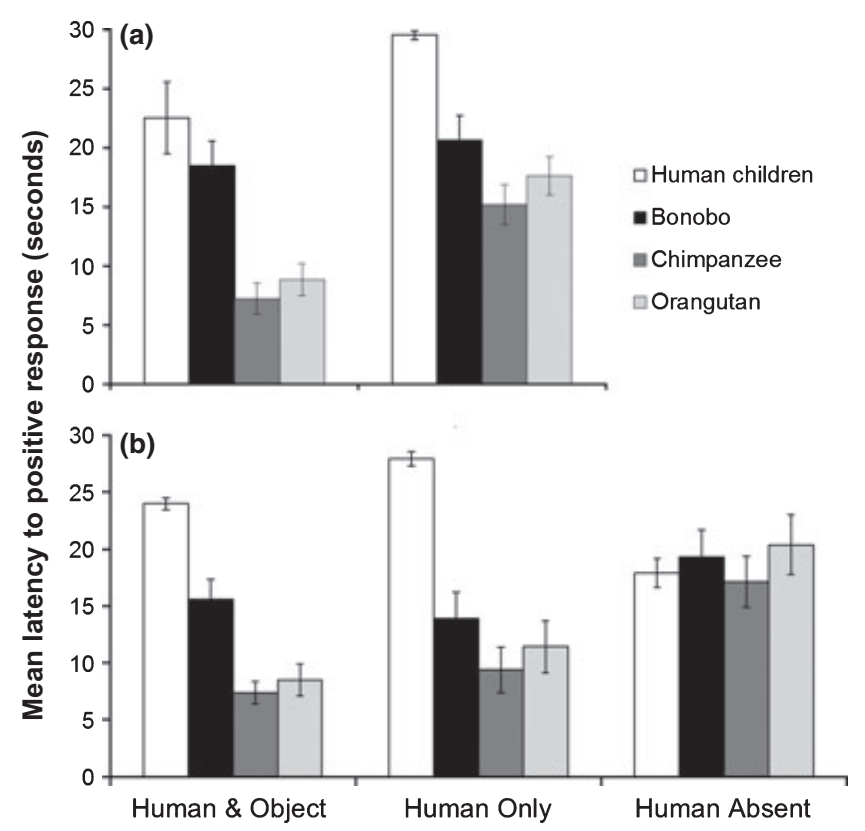

Figure 3 Experiments 2 and 3: The mean latency for bonobos, chimpanzees, orangutans and human children to approach/ show a positive response in the direction of a testing table within 30 seconds when (a) 14 children were tested at a day care without their parents or barriers between themselves and the testing table (Experiment 3) and (b) 105 children were tested at a child laboratory with their parents present and a Plexiglas barrier between themselves and the testing items (Experiment 2). The baseline condition in which a human was absent from the testing table was only run in Experiment 2. 
$253.9=10.767, \quad p<.001), \quad$ species $\quad\left(F_{3}, \quad 169=30.046\right.$, $p<.001)$ and a significant interaction between category and species $\left(F_{4.5,253.9}=21.126, p<.001\right)$. No significant differences were detected for sex and no other interaction between the three factors. Since no sex effect was found, this variable was not included in the following analyses. When contrasting the different species' latencies to respond positively in each category separately, the species differed in their response to both object items $\left(F_{3}\right.$, $\left.{ }_{173}=76.622, p<.001, \eta^{2}=0.57\right)$ and human items $\left(F_{3}\right.$, $\left.173=56.236, p<.001, \eta^{2}=0.49\right)$, but not human absent items $\left(F_{3,173}=0.381, p=.767, \eta^{2}=0.01\right)$. Subsequent, post-hoc tests reveal that all three nonhuman ape species showed a positive response significantly faster than human children when presented with the object and human items $(p<.01$, Dunnett $\mathrm{t} 3$ correction). Replicating Experiment 1, chimpanzees and orangutans approached object items more quickly than bonobos $(p<.02$, Bonferroni correction), while orangutans and chimpanzees did not differ in their approach to object items, and no nonhuman apes differed in their approach toward human items.

When using the latencies to respond positively in the human absent category as a baseline (no human was present), human children were slower to show a positive response to other test items (object items: $t(104)=5.354$, $p<.001$; human items: $t(104)=7.740, \quad p<.001$, paired-sample $t$-test) while chimpanzees and orangutans were quicker to approach other test items when compared to their baseline approach behavior (chimpanzee - object items: $t(23)=4.689, p<.001$; human items: $t(23)=3.146, p=.005$; orangutan - object items: $t(23)=5.434, \quad p<.001$; human items: $t(23)=3.742$, $p=.001$, paired-sample $t$-test). Meanwhile, among the nonhuman apes, bonobos' response had the most similar pattern to the human children although their behavior in most test categories did not differ significantly from their baseline latencies (Table 3; Figure 3).

\section{Discussion}

The findings of Experiment 2 extend those of the first experiment by directly comparing nonhuman apes' and 2.5-year-old human children's response to various forms of novelty. Overall, human children were avoidant in comparison to their baseline response behavior and that of the other ape species (although all four species did not differ in their latency to show a positive response in the baseline item when a human was absent). In contrast to the other apes, children were the only species that showed a slower positive response to test items than the baseline items. Chimpanzee behavior most closely resembles that of orangutans and is highly dissimilar from children and bonobos in their reaction towards new objects. There was no effect of sex for any of the species on any of the categories.

This study was designed to map out temperamental similarities and differences across nonhuman apes and human children by trying as far as possible to use the same method for all species. However, human children were instructed to sit down on a bench at a designated starting point before each trial and were accompanied by a parent. In addition, the testing took place in a room that was empty except for a Plexiglas barrier and relatively new to the children who were introduced to it one day before the study began. One hypothesis is that this set-up was more strange for the human children than the testing situation for the three nonhuman ape species and their avoidance towards the stimuli could be explained by these factors (e.g it is harder for a child because they had to stand up and approach the stimuli alone while their parents sat on the bench without reacting). In order to control for these possibly influential factors we conducted Experiment 3.

\section{Experiment 3}

To address the methodological concerns from Experiment 2, we investigated the response to novelty of 2.5year-old human children in a different observational setting. In contrast to Experiment 2, the testing took place in a familiar room in the children's day care center without Plexiglas barriers and no parent was present who could have an influence on the spontaneous behavior of the child. We then compared these observations to those of bonobos, chimpanzees and orangutans in the same subset of tasks from Experiment 1.

\section{Methods}

\section{Participants}

Fourteen 2.5-year-old human children (range = within 2 months) participated in this study. The human children were tested in different day care centers in Leipzig, Germany (Table 1, ESM).

\section{Experimental design and procedure}

Each subject was presented with a subset of five items that were previously presented to the nonhuman apes in Experiment 1 on the first day (visible). The experimental procedure was identical to that used in the child laboratory in Experiment 2 with the following important exceptions: (1) the testing took place in a familiar room without Plexiglas barriers and no parent was present; (2) the child stood at the starting point next to a seated experimenter who interacted naturally with the child between trials, e.g. by talking about the child's shoes; (3) the testing table was of a height such that subjects could see but not touch objects placed on it or humans seated behind it; and (4) each subject only participated in five items from Experiment 1 (always administered in the same order; Table 2). For analysis the items were grouped into two categories: human items (familiar hu- 
man, unfamiliar human) and object items (film canister, plastic hedgehog and police car). These five items were the same as the visible human and object items used in Experiment 1 (Table 2).

\section{Scoring and analysis}

Subjects' behavior was coded from a videotape using the same measures as in Experiment 1. We then replicated the analysis of Experiment 2 comparing all four species' response behavior against each other on this subset of five items (see ESM for further analysis of duration of positive response and proximity). A second observer independently scored $20 \%$ of the human children trials resulting in high levels of inter-observer reliability (ESM, Table S5).

Since the age of the nonhuman apes ranged from 3 to 22 and all of the human children were 2.5 years old, we investigated the influence of age on the nonhuman apes' observed behavior. Therefore we conducted a Pearson correlation analysis for bonobos, chimpanzees and orangutans separately between the subject ages and the human and object items.

\section{Results}

The behavior of children at the day care replicates the findings from the human children tested in the child laboratory in Experiment 2. Table 3 and Figure 3a show the mean latencies for bonobos, chimpanzees, orangutans and human children to respond positively to items within the two categories: object items and human items. A repeated measures ANOVA, with category (object items and human items) as the within-subjects variable and species and sex as the between-subjects variables, found a main effect of category $\left(F_{1}, 77=40.658\right.$, $p<.001)$ and species $\left(F_{3,77}=15.222, p<.001\right)$, but no significant differences were detected for sex and no interaction between the three factors. Since no sex effect was found, this variable was not included in the following analyses. When contrasting the different species' latencies to show a positive response in the two categories separately, the species again differed in their response to both object items $\left(F_{3,81}=14.496, p<.001, \eta^{2}=0.35\right)$ and human items $\left(F_{3,81}=10.197, p<.001, \eta^{2}=0.27\right)$. Posthoc tests for the human items reveal that all nonhuman apes showed a positive response more quickly than human children ( $p<.003$, Dunnett $\mathrm{t} 3$ correction) while chimpanzees and orangutans showed a positive response to the object items more quickly than both children and bonobos ( $p<.005$, Dunnett $\mathrm{t} 3$ correction). Therefore, again, the day care children avoided novelty and in doing so most closely resembled the behavior of bonobos while chimpanzees and orangutans most closely resembled one another on the same measures.

In addition, we investigated the influence of age on the nonhuman apes' approach behavior. For all three species no significant correlation was found between the latency measure for human items and object items and age (bonobos - human items: $r=0.293, p=.175, N=23$; object items: $r=0.200, p=.349, N=24$; chimpanzees human items: $r=0.092, p=.670, N=24$; object items: $r=-0.188, p=.379, \quad N=24$; orangutans - human items: $\quad r=0.000, \quad p=.999, \quad N=24$; object items: $r=0.130, p=.546, N=24)$. These findings suggest that age played no significant role in the nonhuman apes' response to novelty and this suggests that the species' differences in this study cannot be explained by the age differences between the nonhuman apes and human children, not ruling out the possibility that age would play a role in humans in that task.

\section{Discussion}

The avoidant response pattern of the human children in this experiment replicated the findings from the previous experiment, even after changing the testing situation to a familiar room, without barriers or parents present, and after potentially making an approach easier by allowing children to stand at the starting position. Therefore, regardless of the method used with the children, they were the only species to react in an avoidant manner towards the novel items presented. Interestingly, bonobos, although largely indifferent to the stimuli presented, were the species with the response behavior most similar to that seen in human children. This similarity is strongest in the object items where the behavior of children did not differ from that of bonobos.

\section{General discussion}

The current results provide support for the hypothesis that the human temperament at the age of 2.5 years is highly divergent from that seen in our closest living relatives, the chimpanzee and the bonobo. While all three species of nonhuman apes were either attracted to or indifferent toward novelty, human children avoided the novel items presented. This effect is robust in that it was replicated with children using two different methods; even though these two methods varied factors to potentially increase the confidence of children in response to novel items (i.e. the absence of parents, removing physical barriers, etc.) and the coding criteria were far more generous for human children in the child lab than for nonhuman apes.

Even though the uncertain response to novelty we document here at the age of 2.5 years does not correlate with individual performance in cognitive tasks these same children were tested on later (Herrmann et al., 2007; Herrmann, Call, Hernández-Lloreda, Hare \& Tomasello, 2010), the overall species differences we see here may play a role in explaining the development of uniquely human social cognition. For instance, children's shyer temperamental profile may result in children seeking reassurance from their parents and peers in a way 
that likely provides a species-unique opportunity for social learning and teaching. This more observant stance likely helps children to reflect on the cause of the behavior of others which then leads to more sophisticated social cognitive abilities later in life (Wellman et al., 2011). The lack of correlations between temperament measures and individual variation in performance on the broad range of cognitive tasks in Hermann et al. (2007, 2010) and the correlation between temperament and later false belief performance in Wellman et al. (2011) points to the possibility that infant temperament plays a role in shaping unique human social cognition (i.e. false belief attribution) but plays a smaller role in skills shared with other apes (i.e. the tasks used in Herrmann et al., 2007, were chosen because apes can solve them). Additionally, it might be that the effect of temperamental variation on cognitive skill only expresses itself in humans to a measurable degree in late infancy. Regardless, the approachavoidance behavior of humans as seen in the context tested here is divergent from the behavior seen in all the other ape species tested. With this difference between the human children and nonhuman apes in mind, it is important to note that rearing differences among nonhuman apes had no effect on the apes' response behavior (ESM) and that the majority of the nonhuman apes tested were infants or young juveniles and like the human children were all raised together with humans over many years (ESM; Wobber \& Hare, 2011). However, if anything we would suggest that the interaction with a human experimenter should be more common and less intimidating for human children than for the other ape species. But this was not the case. Therefore, these results suggest that using human experimenters for human and nonhuman apes can provide an informative comparison in regard to their response to novelty as well as cognition (Herrmann et al., 2007; Herrmann, Call, HernandezLloreda, Hare \& Tomasello, 2008; and these findings counter the critique of the use of a human experimenter for nonhuman apes from de Waal, Boesch, Horner \& Whiten, 2008).

These results also support the hypothesis that differences in ecology shape a species' response to uncertainty (Vitale et al., 1991; Clarke \& Lindburg, 1993; Clarke \& Boinski, 1995; Glickman \& Sroges, 1966). Chimpanzees and orangutans are characterized as having evolved in more unpredictable feeding environments than either humans or bonobos (White \& Wrangham, 1988; Malenky \& Wrangham, 1994; Wrangham \& Peterson, 1996; Wrangham et al., 1999; van Schaik, 2004; Furuichi, in press) and both species, although relatively distantly related, were highly similar in their attraction to novelty. Therefore, the bold behavior of chimpanzees and orangutans may play a role in helping these species forage optimally. Indeed, Heilbronner et al. (2008) found that chimpanzees preferred to receive uncertain but more variable food payoffs over more certain food payoffs in a feeding task (bonobos in contrast were risk averse, preferring the more certain option). Therefore, it may be that chimpanzees and orangutans evolved preferences that in many contexts favor risk over certainty. These different species' reactions to uncertainty are consistent with and may be related to their response to novelty in the current study.

The preferences seen here in bonobos can be interpreted to support the hypothesis that they evolved in part in response to a relaxation of intra-group competition and selection against male aggression (Wrangham \& Pilbeam, 2001; Hare \& Wrangham, in preparation; Furuichi, in press). Selection against aggression in domesticated animals often leads to an attenuation of not only stress in novel situations but also exploratory behavior (Künzl \& Sachser, 1999; Künzl, Kaiser, Meier \& Sachser, 2003). Therefore, the largely indifferent response of the bonobos to the novel items presented is consistent with the hypothesis that selection against aggression in this species has also reduced their preference for novelty and uncertainty as seen in domesticated animals. These results make it imperative that our phylogenetic comparisons with humans continue to include both of our closest relatives when testing hypotheses of human evolution (Hare, 2009). In this regard it is noteworthy that Semendeferi, Armstrong, Schleicher, Zilles and van Hoesen (1998) found that both humans and bonobos have a highly diversified posterior orbitofrontal cortex relative to other hominoids - an area implicated in emotional processing.

Although our comparison between species uncovered robust species differences in response to novelty with sex playing no role and although it will be methodologically challenging with apes, in the future it will be important to explore the response of nonhuman apes to conspecifics as well as to humans (e.g. as in Fairbainks, 2001). For example, it is likely that chimpanzees whose intergroup interactions can lead to lethal aggression will respond differently from bonobos who are far more tolerant of strangers (Wrangham, 1999). Bonobos may even be attracted to strangers (i.e. Hare \& Kwetuenda, 2010; Furuichi, in press). In addition, it will be important to track how the response to novelty or uncertainty in human children develops in comparison to that of other apes and how the development of human temperament might then influence species-unique problem solving skills (i.e. it may be that at different ages humans are more or less like other apes in their temperamental profile as observed here for 2.5-year-olds). Finally, it will be important to explore the genetics of temperamental differences. For example, it has been shown for some species that polymorphism in the dopamine receptor D4 gene is associated with variation in measures of noveltyseeking behavior (Fidler, van Oers, Drent, Kuhn, Mueller \& Kempenaers, 2007; Bailey, Breidenthal, Jorgensen, McCracken \& Fairbanks, 2007). Although it is unknown if species and individual temperamental differences among apes are associated with variation in this gene, it is clear that this will be an important candidate to examine in apes. 


\section{Acknowledgements}

We are grateful to the management and animal caregivers at Lola ya Bonobo Sanctuary, Tchimpounga Chimpanzee Sanctuary, Ngamba Chimpanzee Sanctuary, Orangutan Care Centre and Quarantine in Pasir Panjang and the Wolfgang Köhler Primate Research Center (ESM). We also thank the Ministry of Environment in the Democratic Republic of Congo (research permit \#MIN.RS/SG/004/2009), the Congolese Ministere de la Recherche Scientifique et de l'Innovation Technique in the Republic of Congo (research permit: 009/MRS/ DGRST/DMAST), the Ugandan National Council for Science and Technology and the Uganda Wildlife Authority, the Indonesian Institute of Sciences (LIPI) and the Indonesian Ministry of Forestry for their support of our research. Special thanks go to A. Loose, M. Schäfer, K. Greve, E. Graf, V. Wobber, V. Woods and S. Hastings for their enormous help with organizing, data collection and coding. In addition we thank J. Uebel, L. Jorschik, A. Gampe, A.P. Melis, P. Jahn and A. Rosati for their help in various ways to make this study successful. We also thank the parents and children who participated in the study. The research of EH is supported by a grant from the Studienstiftung des Deutschen Volkes. This work was supported in part by European Research Commission Advanced Grant Agreement 233297 and by National Science Foundation grant NSF-BCS-27552 and NSFBCS-25172 to BH.

\section{References}

Bailey, J.N., Breidenthal, S.E., Jorgensen, M.J., McCracken, J.T., \& Fairbanks, L.A. (2007). The association of DRD4 and novelty seeking is found in a nonhuman primate model. Psychiatric Genetics, 17, 23-27.

Bolig, R., Price, C.S., O’Neill, P.L., \& Suomi, S.J. (1992). Subjective assessment of reactivity level and personality traits of rhesus monkeys. International Journal of Primatology, 13, 287-306.

Buirski, P., Plutchik, R., \& Kellerman, H. (1978). Sex differences, dominance, and personality in the chimpanzee. Animal Behaviour, 26, 123-129.

Clarke, A.S., \& Boinski, S. (1995). Temperament in nonhuman primates. American Journal of Primatology, 37, 103-125.

Clarke, A.S., \& Lindburg, D.G. (1993). Behavioral contrasts between male cynomolgus and lion-tailed macaques. American Journal of Primatology, 29, 49-59.

Coleman, K., \& Wilson, D.S. (1998). Shyness and boldness in pumpkinseed sunfish: individual differences are contextspecific. Animal Behaviour, 56, 927-936.

Crawford, M.P. (1938). A behavior rating scale for young chimpanzees. Journal of Comparative Psychology, 26, 79-91.

de Waal, F., Boesch, C., Horner, V., \& Whiten, A. (2008). Comparing social skills of children and apes. Science, 319, 569.

de Waal, F., \& Lanting, F. (1997). Bonobo: The forgotten ape. Berkeley, CA: University of California Press.
Dutton, D.M., Clark, R.A., \& Dickins, D.W. (1997). Personality in captive chimpanzees: use of novel rating procedure. International Journal of Primatology, 18, 539-552.

Fairbanks, L.A. (2001). Individual differences in response to a stranger: social impulsivity as a dimension of temperament in vervet monkeys (Cercopithecus aethiops sabaeus). Journal of Comparative Psychology, 115, 22-28.

Fairbanks, L.A., \& McGuire, M.T. (1993). Maternal protectiveness and response to the unfamiliar in vervet monkeys. American Journal of Primatology, 30, 119-130.

Fairbanks, L.A., Newman, T.K., Bailey, J.N., Jorgensen, M.J., Breidenthal, S.E., Ophoff, R.A., Comuzzie, A.G., Martin, L.J., \& Rogers, J. (2004). Genetic contributions to social impulsivity and aggressiveness in vervet monkeys. Biological Psychiatry, 55, 642-647.

Fidler, A.E., van Oers, K., Drent, P.J., Kuhn, S., Mueller, J.C., \& Kempenaers, B. (2007). Drd4 gene polymorphisms are associated with personality variation in a passerine bird. Proceedings of the Royal Society B, 274, 1685-1691.

Freeman, H.D., \& Gosling, S.D. (2010). Personality in nonhuman primates: a review and evaluation of past research. American Journal of Primatology, 72, 653-671.

Furuichi, T. (in press). Contribution of female bonobos to the peaceful nature of the society. Evolutionary Anthropology.

Glickman, S.E., \& Sroges, R.W. (1966). Curiosity in zoo animals. Behaviour, 26, 151-188.

Gosling, S.D. (2001). From mice to men: what can we learn about personality from animal research? Psychological Bulletin, 127, 45-86.

Gosling, S.D., \& John, O.P. (1999). Personality dimensions in non-human animals: a cross-species review. Current Directions in Psychological Science, 8, 69-75.

Hare, B. (2007). From nonhuman to human mind: what changed and why. Current Directions in Psychological Science, 16, 60-64.

Hare, B. (2009). What is the effect of affect on bonobo and chimpanzee problem solving? In A. Berthoz \& Y. Christen (Eds.), Neurobiology of 'umwelt': How living beings perceive the world (pp. 89-102). Berlin: Springer-Verlag.

Hare, B., \& Kwetuenda, S. (2010). Bonobos voluntarily share their own food with others. Current Biology, 20, R230 R231.

Hare, B., Melis, A., Woods, V., Hastings, S., \& Wrangham, R. (2007). Tolerance allows bonobos to outperform chimpanzees in a cooperative task. Current Biology, 17, 619623.

Hare, B.A., \& Tomasello, M. (2004). Chimpanzees are more skillful in competitive than in cooperative cognitive tasks. Animal Behaviour, 68, 571-581.

Hare, B., \& Tomasello, M. (2005). The emotional reactivity hypothesis and cognitive evolution. Trends in Cognitive Sciences, 10, 464 465.

Hare, B., \& Wrangham, R. (in preparation). Selection against aggression results in convergence in bonobos, domesticated animals and humans? Bioessays.

Hebb, D.O. (1949). Temperament in chimpanzees: I. Method and analyses. Journal of Comparative and Physiological Psychology, 42, 192-206.

Heilbronner, S.R., Rosati, A.G., Stevens, J.R., Hare, B., \& Hauser, M.D. (2008). A fruit in the hand or two in the bush? Divergent risk preferences in chimpanzees and bonobos. Biology Letters, 4, 246-249. 
Herrmann, E., Call, J., Hernandez-Lloreda, M.V., Hare, B., \& Tomasello, M. (2007). Humans have evolved specialized skills of social cognition: the cultural intelligence hypothesis. Science, 317, 1360-1366.

Herrmann, E., Call, J., Hernandez-Lloreda, M.V., Hare, B., \& Tomasello, M. (2008). Response to de Waal et al. Science, 319, 570.

Herrmann, E., Call, J., Hernández-Lloreda, M., Hare, B., \& Tomasello, M. (2010). Cognition in chimpanzees and children has different factor structure. Psychological Science, 21, 102-110.

Herrmann, E., \& Tomasello, M. (2006). Apes' and children's understanding of cooperative and competitive motives in a communicative situation. Developmental Science, 9, 518-529.

Higley, J.D., \& Suomi, S.J. (1989). Temperamental reactivity in non-human primates. In G.A. Kohnstamm, J.E. Bates, \& M.K. Rothbart (Eds.), Temperament in childhood (pp. 153167). New York: John Wiley \& Sons.

Kagan, J. (1994). Galen's prophecy. New York: Basic Books.

Kagan, J. (1997). Temperament and the reactions to unfamiliarity. Child Development, 68, 139-143.

Kagan, J., Reznick, J.S., \& Gibbons, J. (1989). Inhibited and uninhibited types of children. Child Development, 60, 838-845.

Kagan, J., Reznick, J.S., \& Snidman, N. (1988). Biological bases of childhood shyness. Science, 240, 167-171.

Kagan, J., \& Snidman, N. (2004). The long shadow of temperament. Cambridge, MA: Belknap Press of Harvard University Press.

King, J.E., \& Figueredo, A.J. (1997). The five-factor model plus dominance in chimpanzee personality. Journal of Research in Personality, 31, 257-271.

King, J.E., Weiss, A., \& Farmer, K.H. (2005). A chimpanzee (Pan troglodytes) analogue of cross-national generalization of personality structure: zoological parks and an African sanctuary. Journal of Personality, 73, 389-410.

King, J.E., Weiss, A., \& Sisco, M.M. (2008). Aping humans: age and sex effects in chimpanzee (Pan troglodytes) and human (Homo sapiens) personality. Journal of Comparative Psychology, 122, 418-427.

Krebs, J.R., \& Davies, N.B. (1993). Introduction to behavioural ecology. Oxford: Blackwell Science.

Künzl, C., Kaiser, S., Meier, E., \& Sachser, N. (2003). Is a wild mammal kept and reared in captivity still a wild animal? Hormones and Behavior, 43, 187-196.

Künzl, C., \& Sachser, N. (1999). The behavioural endocrinology of domestication: a comparison between the domestic guinea pig (Cavia aperea f. porcellus) and its wild ancestor, the cavy (Cavia aperea). Hormones and Behavior, 35, 28-37.

Lilienfeld, S.O., Gershon, J., Duke, M., Marino, L., \& de Waal, F.B.M. (1999). A preliminary investigation of the construct of psychopathic personality (psychopathy) in chimpanzees (Pan troglodytes). Journal of Comparative Psychology, 113, 365-375.

Malenky, R.K., \& Wrangham, R.W. (1994). A quantitive comparison of terrestrial herbaceous food consumption by Pan paniscus in the Lomako forest, Zaire, and Pan troglodytes in the Kibale forest, Uganda. American Journal of Primatology, 32, 1-12.

Melis, A.P., Hare, B., \& Tomasello, M. (2006). Chimpanzees recruit the best collaborators. Science, 311, 1297-1300.

Mettke-Hofmann, C., Wink, M., Winkler, H., \& Leisler, B. (2004). Exploration of environmental changes related to lifestyle. Behavioral Ecology, 16, 247-254.
Parker, C.E. (1974). Behavioral diversity in ten species of nonhuman primates. Journal of Comparative and Physiological Psychology, 87, 930-937.

Réale, D., Reader, S.M., Sol, D., McDougall, P., \& Dingemanse, N. (2007). Integrating animal temperament within ecology and evolutionary biology. Biological Reviews, 82, 291-318.

Robinson, J.L., Kagan, J., Reznick, J.S., \& Corley, R. (1992). The heritability of inhibited and uninhibited behavior: a twin study. Developmental Psychology, 28, 1030-1037.

Rosati, A.G., Stevens, J.R., Hare, B., \& Hauser, M.D. (2007). The evolutionary origins of human patience: temporal preferences in chimpanzees, bonobos, and human adults. Current Biology, 17, 1663-1668.

Rothbart, M.K., Ahadi, S.A., Hershey, K., \& Fisher, P. (2001). Investigations of temperament at three to seven years: the Children's Behavior Questionnaire. Child Development, 72, 1394-1408.

Rothbart, M.K., \& Derryberry, D. (1981). Development of individual differences in temperament. In M.E. Lamb \& A.L. Brown (Eds.), Advances in developmental psychology (Vol. 1, pp. 37-86). Hillsdale, NJ: Erlbaum.

Rothbart, M.K., Derryberry, D., \& Hershey, K. (2000). Stability of temperament in childhood: laboratory infant assessment to parent report at seven years. In V.J. Molfese \& D.L. Molfese (Eds.), Temperament and personality development across the life span (pp. 85-119). Hillsdale, NJ: Erlbaum.

Semendeferi, K., Armstrong, E., Schleicher, A., Zilles, K., \& van Hoesen, G.W. (1998). Limbic frontal cortex in hominoids: a comparative study of area 13. American Journal of Physical Anthropology, 106, 129-155.

Singh, S.D., \& Manocha, S.N. (1966). Reactions of the rhesus monkey and the langur in novel situations. Primates, 7, 259 262.

Stevenson-Hinde, J., Zunz, M., \& Stillwell-Barnes, R. (1980). Behaviour of one-year-old rhesus in a strange situation. Animal Behavior, 28, 266-277.

Thomas, A., \& Chess, S. (1977). Temperament and development. New York: Brunner/Mazel.

Tomasello, M., Carpenter, M., Call, J., Behne, T., \& Moll, H. (2005). Understanding and sharing intentions: the origins of cultural cognition. Behavioral and Brain Sciences, 28, 675-691.

Torigoe, T. (1985). Comparison of object manipulation among 74 species of nonhuman primates. Primates, 26, 182-194.

Trut, L. (1999). Early canid domestication: the farm-fox experiment. American Scientist, 87, 160-169.

Uher, J., Asendorpf, J.B., \& Call, J. (2008). Personality in the behaviour of great apes: temporal stability, cross-situational consistency and coherence in response. Animal Behaviour, 75, 99-112.

van Schaik, C. (2004). Among orangutans. Cambridge, MA: Belknap Press of Harvard University Press.

Vitale, A.F., Visalberghi, E., \& De Lillo, C. (1991). Responses to a snake model in captive crabeating macaques (Macaca fascicularis) and captive tufted capuchins (Cebus apella). International Journal of Primatology, 121, 277-286.

Warneken, F., \& Tomasello, M. (2006). Altruistic helping in human infants and young chimpanzees. Science, 311, 13011303.

Wellman, H.M., Lane, J., LaBounty, J., \& Olson, S.L. (2011). Observant, nonaggressive temperament predicts theory of mind development. Developmental Science, 14, 319-326. 
White, F.J., \& Wrangham, R.W. (1988). Feeding competition and patch size in the chimpanzee species Pan paniscus and Pan troglodytes. Behaviour, 105, 148-164.

Wobber, V., \& Hare, B. (2011). Psychological health of orphan bonobos and chimpanzees in African sanctuaries. PLoS One, 6 (6), e17147.

Wobber, V., Hare, B., Maboto, J., Lipson, S., Wrangham, R., \& Ellison, P. (2010b). Differential reactivity of steroid hormones in chimpanzees and bonobos when anticipating food competition. Proceedings of the National Academy of Sciences, USA, 107, 12457-12462.

Wobber, V., Wrangham, R., \& Hare, B. (2010a). Evidence for delayed development of social behavior and cognition in bonobos relative to chimpanzees. Current Biology, 20, 226 230.

Wrangham, R.W. (1999). The evolution of coalitionary killing. Yearbook of Physical Anthropology, 42, 1-30.
Wrangham, R.W., Jones, J.H., Laden, G., Pilbeam, D., \& Conklon-Brittain, N. (1999). The raw and the stolen. Current Anthropology, 40, 567-594.

Wrangham, R.W., \& Peterson, D. (1996). Demonic males: Apes and the origins of human violence. Cambridge, MA: Harvard University Press.

Wrangham, R.W., \& Pilbeam, D. (2001). African apes as time machines. In B.M.F. Galdikas, N. Briggs, L.K. Sheeran, G.L. Shapiro, \& J. Goodall (Eds.), All apes great and small, Volume 1: Chimpanzees, bonobos, and gorillas (pp. 5-18). New York: Kluwer Academic/Plenum.

Yerkes, R.M., \& Yerkes, A.W. (1936). Nature and conditions of avoidance (fear) responses in chimpanzees. Journal of Comparative Psychology, 21, 53-66.

Received: 24 June 2010

Accepted: 9 June 2011 